\title{
Pleomorphic Adenoma of the Trachea
}

\author{
Shigehisa Kajikawa ${ }^{a}$ Masahide Oki ${ }^{a}$ Hideo Saka ${ }^{a}$ Suzuko Moritani ${ }^{b}$ \\ Departments of ${ }^{\text {a }}$ Respiratory Medicine and ${ }^{\mathrm{b}}$ Pathology, Nagoya Medical Center, Nagoya, Japan
}

A 55-year-old man with a tracheal tumor was referred to our institution for bronchoscopic diagnosis and treatment. He had a 2-year history of dyspnea with wheezing, and was given a diagnosis of asthma by his family doctor. His symptoms were not alleviated by treatment for asthma so he was referred to another hospital for further evaluation. A chest CT revealed a polypoid tumor narrowing the distal trachea (fig. 1). Positron emission tomography showed slight fluorodeoxyglucose uptake of the tumor, but no other abnormalities were found.

Therapeutic bronchoscopy under general anesthesia was performed using a rigid and flexible bronchoscope, which showed a polypoid, lobulated, glossy tumor with telangiectatic surface protruding from the anterior wall of the trachea (fig. 2). The tumor was resected with argon plasma coagulation, electrocautery and rigid bronchoscopic coring. A diagnosis of pleomorphic adenoma was made on the histopathology with a sheet-like structure of myoepithelial and epithelial cells embedded in a myxomatous stroma and no mitotic figures (fig. 3). The patient experienced immediate relief of his respiratory symptoms with pulmonary function improvement $\left(\mathrm{FEV}_{1}\right.$ from 0.79 to $2.86 \mathrm{l}$, peak expiratory flow from 1.44 to $6.43 \mathrm{l} / \mathrm{s}$ ), and was discharged 5 days after the procedure. He has since been under careful observation and there has been no evidence of recurrence in bronchoscopy and chest CT at 7 months after the procedure.

\section{KARGER}

Fax +4161306 1234 E-Mail karger@karger.ch www.karger.com
(C) 2010 S. Karger AG, Basel 0025-7931/10/0805-0433\$26.00/0

Accessible online at:

www.karger.com/res

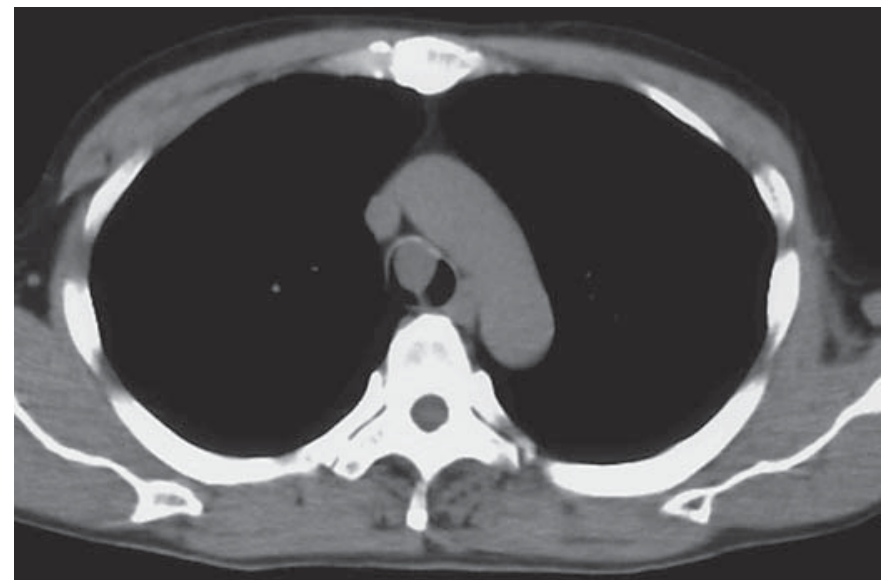

Fig. 1. Chest CT showing an intratracheal polypoid tumor.

Pleomorphic adenoma is a common neoplasm of salivary glands, but its occurrence in the trachea is very rare [1]. Tracheal tumors, including tracheal pleomorphic adenoma, often cause obstructive symptoms such as dyspnea and wheezing mimicking asthma, leading to delay in diagnosis [2]. Because of the rarity, consensus with regard to clinical behavior, management or prognosis is

Shigehisa Kajikawa

Department of Respiratory Medicine, Nagoya Medical Center

4-1-1 Sannomaru, Naka-ku

Nagoya 460-0001 (Japan)

Tel. +81 52951 1111, Fax +81 52951 0664, E-Mail shigeokazy@yahoo.co.jp 

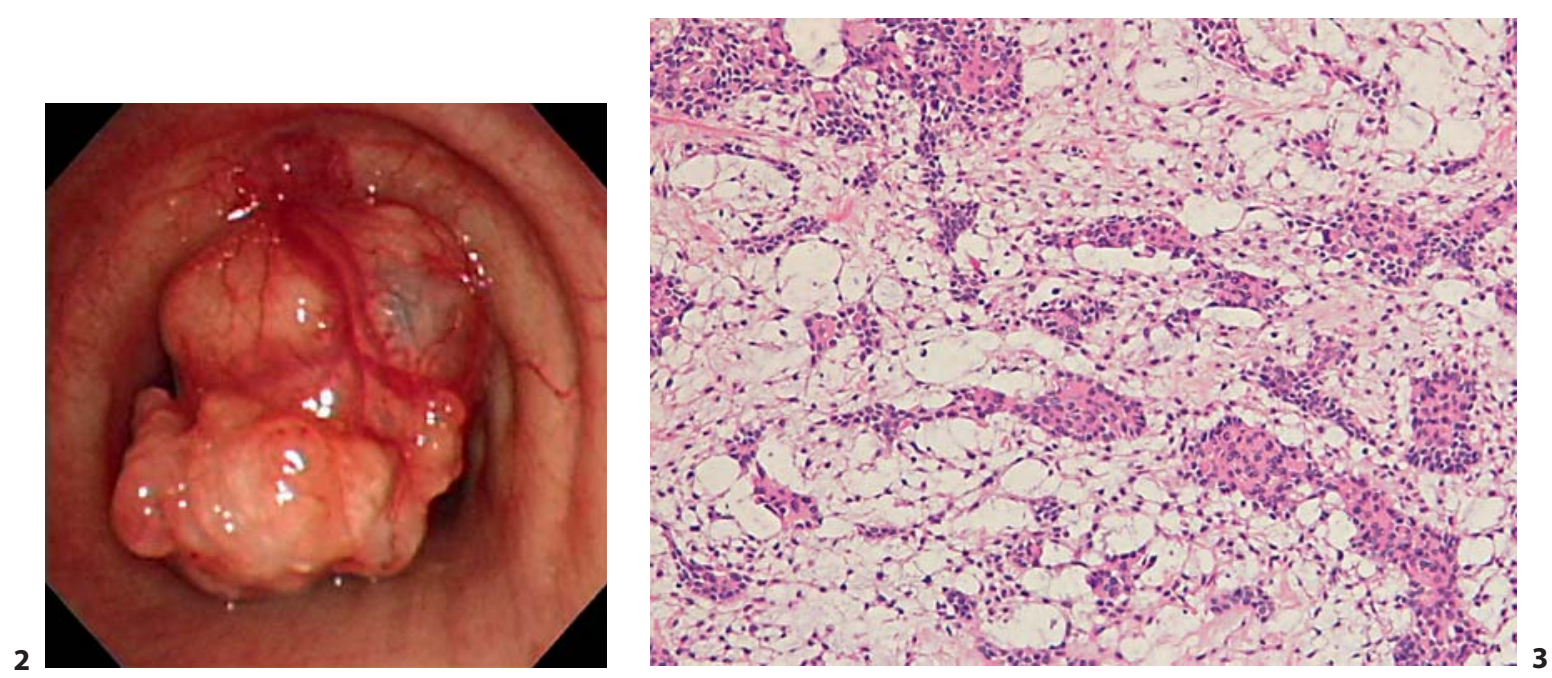

Fig. 2. Bronchoscopic view of the tumor obstructing the distal trachea.

Fig. 3. Histologic specimen showing sheets of myoepithelial and epithelial cells in a myxomatous stroma. HE. Original magnification $\times 200$.

lacking. However, needless to say, careful follow-up after the resection is necessary because recurrence, which may depend on the tumor size, extent of local infiltration and level of mitotic activity, has been occasionally reported [1].
References

1 Moran CA, Suster S, Askin FB, Koss MN, Dumon JF: Benign and malignant salivary gland-type mixed tumors of the lung: clinicopathologic and immunohistochemical study of eight cases. Cancer 1994;73:2481-2490.

2 Aribas OK, Kanat F, Avunduk MC: Pleomorphic adenoma of the trachea mimicking bronchial asthma: report of a case. Surg Today 2007;37:493-495. 